\title{
Analyzing Research Productivity of Indian Institutes of Technology
}

\author{
Tasleem Arif \\ Department of Information Technology \\ Baba Ghulam Shah Badshah University Rajouri \\ Jammu \& Kashmir, India
}

\begin{abstract}
A total of 1082 research publications of 111 faculty members working with Computer Science Engineering departments of four top ranked Indian Institutes of Technology were extracted from their websites and DBLP. Analysis of the extracted publications over a five year period from 2011 to 2015 unravel some important aspects about the research and authorship trends in these institutes of national importance. Study shows that there are huge differences in research productivity in terms number of publications, growth of literature, per capita productivity, etc. in these institutes that were established with the same mandate and are working on same lines. IIT Madras has outperformed the other three IITs in all aspects under study with highest number of publications, production of joint publications and per capita productivity.
\end{abstract}

\section{Keywords}

Co-authorship, Research Productivity, Indian Institute of Technology.

\section{INTRODUCTION}

In this fast changing and ever emerging world, measuring academic productivity of institutes and people working with them is neither straightforward nor easy. There are a number of factors like teaching, research publications, sponsored projects, consultancy, thesis supervision, etc. which contribute towards academic productivity. Some of these are tangible and easy to quantify whereas others are hard to quantify as there are not widely accepted parameters. Teaching-learning quality is seldom measured adequately - in part because the assessment of teaching effectiveness is not easy. The feedback methodology, commonly used to qualitatively measure is widely recognized as inadequate [1].

In recent years research output has been the focus of higher education particularly science and technical education. Global rankings also accord higher rankings to institutes with high research productivity. This can be partly attributed to research productivity being tangible, easier to measure than other kinds of academic work and being well documented [2]. Thus, research is not only the gold standard, but almost the only semi-reliable variable. But even measuring research productivity is challenging because of certain problems arising out of indexing issues, author name ambiguity, etc. Indexing of publications is a major issue as not all of the publications are indexed in well known indices like, Science Citation Index, Web of Science or Scopus, DBLP, or their equivalents for other disciplines. These indices also favor journals publishing in English. But it has been observed that the global rankings count journals that are indexed primarily in these global indices [1].
Indian Institutes of Technology (IITs) have been branded as institutes of excellence. There are a number of factors that contribute to their being the most sought after institutes both for the students as well as the faculty. Almost all the faculty members in IITs have Ph.Ds. In fact IITs account for more than sixty percent of $\mathrm{Ph}$.Ds produced in engineering throughout the entire country [3]. The quality of faculty is a major strength enjoyed by these institutes. The performance of these institutes is directly related to the research interests of their faculty members as it impacts their teaching, govern their consultancy preferences and enable their continuing education.

IITs have been dominating the technical education in India since the inception of first Indian Institute of Technology at Kharagpur in West Bengal in the year 1950. A number of such institutes have been started since then at different places throughout the entire length and breadth of the country. As per a report published in India Today on June 5, 2014, IITs have been dominating the top ten slots in engineering colleges in India. IIT Kanpur, IIT Delhi, IIT Kharagpur and IIT Madras are among the six IITs that find a place in top ten institutes in INDIA TODAY Nelisen Best Colleges Survey 2014 [4]. Research productivity is one important factor that has traditionally been used by rating agencies internationally to rank institutes of higher learning. In fact, research productivity is one such attribute that has been documented the most and somehow efficiently also [2].

The purpose of this study is to examine the research productivity of these four institutes of technology as evidenced by the number of research papers published during the period under investigation. In addition, this study also intends to examine the growth pattern, authorship patterns, coauthorships, per capita productivity, etc. from the publications data of these institutes.

\section{RELATED WORK}

Measuring academic productivity is not a new phenomenon. A good number of studies have been performed internationally over last few decades to examine various aspects of the productivity of individuals and institutions of higher education $[2,5,6,7,8,9,10,11,12,13,14,15,16,17$, 18]. Majority of these studies have focused on research output in terms of research publications produced [11]. Thus assessments of individual and departmental research accomplishments are most often based primarily on the number of publications produced during a specific time window.

Of late some studies have been directed towards measuring research productivity in the Indian context. Bala and Gupta [14] use publications data of people working with 
Government Medical College and Hospital Chandigarh from Scopus for a period of sixteen years from 1992-2007. Using this data they analyzed growth pattern, research output and its impact in terms of citations, collaboration patterns and which characteristics make authors and papers achieve high impacts. Although the percentage of articles that were cited once or more is more than 50 percent, a negligible number of papers received more than ten citations. This gives some idea about the quality of the papers published during the period under investigation. This can be attributed to low degree of international collaboration as only about 2 percent of the total publications during this period have an author from abroad i.e. international collaborations are not a priority for the institute under consideration.

Sharma [15] pointed towards high degree of collaboration in 2603 research articles published by scientists of Central Potato Research Institute, Shimla, during 1991 to 2007. In fact around 83 percent of the papers published during the period under investigation were joint publications. Majhi and Maharana [16] use publications data of 120 researchers associated with physical science departments of Sambalpur University indexed by Scopus. A total of 417 papers were published with per capita productivity of 3.475 during 1971 to 2010. Around 94 percent of the papers are joint publications indicating that the people working in these departments prefer working jointly and sharing their knowledge and expertise with their colleagues and peers.

In one of the related studies, Jeevan and Gupta [10] use Scopus indexed journal publications of nine departments of IIT Kharagpur to analyze them from the point of view of research productivity. During the three years period of the study a total of 1172 papers were published. The degree of collaboration is low as only around 48 percent of the total publications have two or more authors. This is in contrast with other studies as around 80 percent of the publications are coauthored ones. However, IIT Kanpur has around 24 percent of the papers co-authored internationally which is not the case with other institutes where such studies have been conducted.

Wani et al. [18] conducted an extensive study of research productivity of IIT Delhi over a period of 45 years from 1964 to 2010. Analysis of 15476 publications indexed by Scopus reveals important facts about the collaboration patterns. It was observed that only around 8 percent of the papers have international co-authors, whereas only around 28 percent of the papers have authors from outside IIT Delhi. The study is silent about the percentage of single or co-authored papers. Arif et al. [2] analyse publications data from a different perspective. They apply social network analysis metrics to study research productivity and collaborations. They identify important individuals as quantified from the values of social network analysis metrics. Publications data obtained from the respective websites of computer science departments of four IITs (Kanpur, Kharagpur, Delhi and Madras) were used to analyse the co-authorship networks extracted from this data. It was pointed out that the level of intradepartmental collaboration was grim during the period of investigation (2006-2011) with IIT-Delhi having very low percentage of people collaborating with each other.

\section{METHODOLOGY}

Since the purpose of the study is to analyze the research productivity of particular departments of some institutes, we obtained publications data of faculty members of Computer Science Engineering departments of these four IITs. The period of investigation has been restricted for five years from 2011 to 2015. We first obtained the list of people working as fulltime faculty in these departments. Publications data of these faculty members was extracted either from their homepages or from some indexing service. Wherever, this data was not available on their homepages directly, it was obtained from DBLP. This data was not in a condition that it could have been used directly for analysis purposes. It was first cleaned and data from all the sources brought in a common format so as to make it useful for any further processing.

The publications data was exported from their respective sources and stored in a database. Using a java based computer program we extracted the number of publications for each year under consideration, co-authorship patterns and number of authors for each of these publications. In addition to this the said program also calculated the rate-of-growth of publications for each of the years taking 2011 as base year. The rate-of-growth was not calculated for the year 2015 as the entire number of publications for this year was not available at this point of time. The statistics of the dataset for the corresponding period are listed in Table-1.

Table-1: Statistics of the dataset.

\begin{tabular}{|l|c|c|c|c|c|c|c|}
\hline \multirow{2}{*}{ IIT } & \multirow{2}{*}{ Faculty } & \multicolumn{5}{|c|}{ Number of Publications in } & \multirow{2}{*}{ Total } \\
\cline { 3 - 8 } & & $\mathbf{2 0 1 1}$ & $\mathbf{2 0 1 2}$ & $\mathbf{2 0 1 3}$ & $\mathbf{2 1 0 4}$ & $\mathbf{2 0 1 5}$ & \\
\hline Kanpur & 25 & 17 & 42 & 27 & 14 & 3 & 103 \\
\hline Delhi & 27 & 62 & 71 & 72 & 69 & 14 & 288 \\
\hline Kharagpur & 32 & 40 & 69 & 70 & 20 & 1 & 200 \\
\hline Madras & 27 & 113 & 116 & 126 & 108 & 28 & 491 \\
\hline \multicolumn{1}{|c|}{ Total } & $\mathbf{1 1 1}$ & $\mathbf{2 3 2}$ & $\mathbf{2 9 8}$ & $\mathbf{2 9 5}$ & $\mathbf{2 1 1}$ & $\mathbf{4 6}$ & $\mathbf{1 0 8 2}$ \\
\hline
\end{tabular}

\section{ANALYSIS AND DISCUSSIONS}

From Table-1 it can be observed that of all these four IITs, IIT Kanpur has least number of publications and IIT Madras has the most. 2012 has been the most productive year in terms of number of publications for each of these four IITs, whereas 2014 has been the least productive. Figure-1 shows the number of publications for each of the IITs for the period under investigation, whereas Figure-2 shows the rate-ofgrowth, in percentage terms, of research output in terms of number of publications produced. From this figure it becomes amply clear that except 2012 there has been a sharp decline in the growth rate of the number of publications produced when compared to those of the previous year. However, IIT Madras has shown almost consistent performance during all these years. 


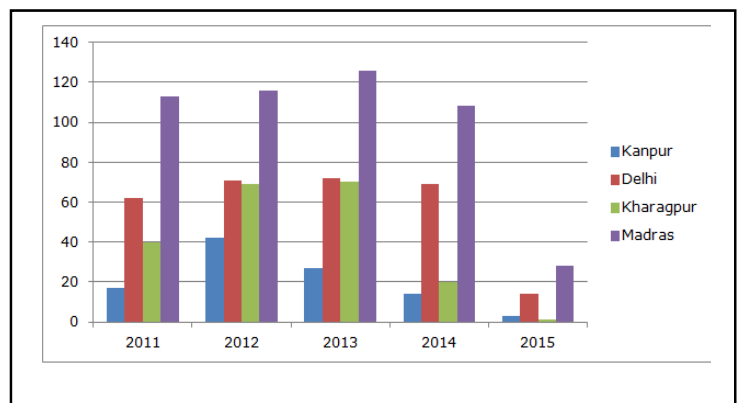

Figure-1: Number of papers published each year for the period under investigation

Table 2 shows the authorship patterns in these publications. These trends have been shown in graph presented in Figure-3. It can be observed that only $1.94 \%$ of the total publications have a single author, $25.88 \%$ have two authors, $37.52 \%$ have three authors, $18.58 \%$ have four authors, $7.3 \%$ have five authors, whereas $8.78 \%$ have more than five authors. Thus the percentage of joint publications i.e. publications have two or more authors is an impressing $98.06 \%$. This is clear indication that the faulty members working in the department under consideration of these four IITs have a great affinity for working jointly and prefer to have great amount of collaboration when it comes to research publications. Table- 2 also shows the maximum number of authors in a research publication. IIT Madras has publications with up to 13 authors, followed by IIT Delhi with a maximum of 12 authors.

Table-2: Authorship pattern

\begin{tabular}{|l|c|c|c|c|c|c|c|c|}
\hline \multirow{2}{*}{ IIT } & \multirow{2}{*}{ Pubs } & \multicolumn{7}{|c|}{ Authors } \\
\cline { 4 - 9 } & & $\mathbf{1}$ & $\mathbf{2}$ & $\mathbf{3}$ & $\mathbf{4}$ & $\mathbf{5}$ & $>\mathbf{5}$ & Max. \\
\hline Kanpur & 103 & 2 & 48 & 34 & 11 & 6 & 2 & 7 \\
\hline Delhi & 288 & 6 & 27 & 118 & 73 & 25 & 39 & 12 \\
\hline Kharagpur & 200 & 4 & 30 & 74 & 48 & 19 & 25 & 9 \\
\hline Madras & 491 & 9 & 175 & 180 & 69 & 29 & 29 & 13 \\
\hline Total & $\mathbf{1 0 8 2}$ & $\mathbf{2 1}$ & $\mathbf{2 8 0}$ & $\mathbf{4 0 6}$ & $\mathbf{2 0 1}$ & $\mathbf{7 9}$ & $\mathbf{9 5}$ & $\mathbf{1 3}$ \\
\hline
\end{tabular}

The average per capita productivity for the period under investigation for all these institutes was 9.81. However, there is huge gap between the per capita productivity of individual institutions. IIT Kanpur has the lowest per capita productivity at 4.12 articles per faculty for the entire period. This value is 10.67 for IIT Delhi, 6.25 for IIT Kanpur and 18.19 for IIT Madras. This further proves the research potential of IIT Madras. From the analysis of extracted and derived statistics it can be concluded that of all these four IITs, IIT Madras has emerged as a leader in terms of number of publications, per capita productivity, rate-of-growth of the literature produced, percentage of joint publications and maximum number of authors for an individual publication, during the period under consideration.

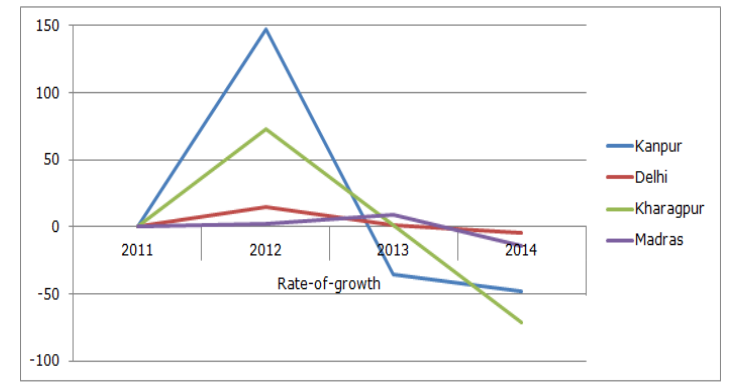

Figure-2: Rate-of-growth of research productivity from 2011 to 2014.

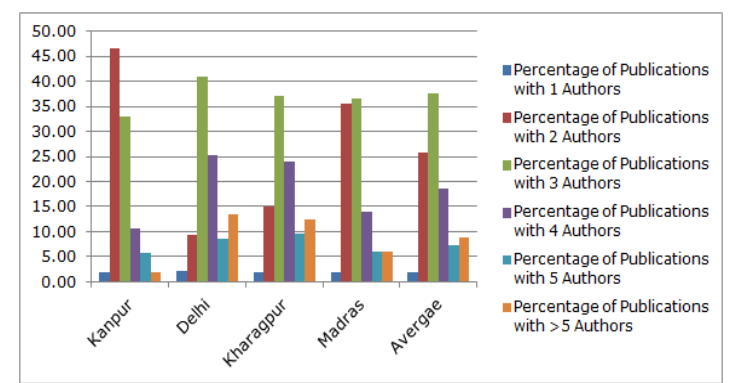

Figure-3: Percentage of publications and number of authors

\section{CONCLUSIONS}

The purpose of this study was to compare and contrast four premier institutes of higher learning in India in terms of their research output evidenced by the number of publications produced during the period 2011-2015. Bibliometric analysis of the publications data throws some light on the level of collaboration in each of these institutes. It becomes amply clear that these researchers are not working in close confines of their rooms but work with other and produced research publications with around 98\% of them being co-authored. There is team spirit among these researchers. It has been observed that the per capita productivity of majority of these institutes is very low and there is need for a lot of improvement considering the status and amount of money being pumped by the government in these institutions. These institutes also need to work on achieving considerable amount of rate-of-growth in research output.

\section{REFERENCES}

[1] Altbach P G, What counts for academic productivity in research universities?, International Higher Education, 79 (2015) 6-7.

[2] Arif, T, Ali, R and Asger, M, Scientific co-authorship social networks: A case study of computer science scenario in India, International Journal of Computer Applications, 52 (12), 2012, 38-45.

[3] Kakodkar, A, Taking IITs to Excellence and Greater Relevance. Report: Available at: http://www.iiti.ac.in/Administration/Kakodkar\%20Com mittee\%20Report.pdf (Last Accessed: 10-04-2015).

[4] INDIA TODAY Nelisen Best Colleges Survey 2014:http://indiatoday.intoday.in/bestcolleges/2014/ranks .jsp?ST=Engineering \&LMT $=2 \& \mathrm{Y}=2014 \quad$ (Last Accessed: 05-04-2015).

[5] Baird, L, What characterizes a productive research department? Research in Higher Education, 25 (1986) 


\section{1-225.}

[6] Baird, L, Publication productivity in doctoral research departments: Interdisciplinary and intradisciplinary factors. Research in Higher Education, 32 (1991) 303318.

[7] Braxton, J and Bayer, A, Assessing faculty scholarly performance. In: Cresswell, J. W. (ed.), Measuring Faculty Research Performance, New Directions for Institutional Research, no. 50 (1986) Jossey-Bass, San Francisco, pp. 25-42.

[8] Creamer, E Assessing faculty publication productivity: Issues of equity. ASHEERIC Higher Education Report Volume 26(2) (1998), The George Washington University, Graduate School of Education and Human Development, Washington, DC.

[9] Golden, J, and Carstensen, F V, Academic research productivity, department size and organization: further results, comment. Econ. Educ. Rev. 11 (1992) 153-160.

[10] Tien, F, and Blackburn, R, Faculty rank system, research motivation, and faculty research productivity, Journal of Higher Education, 67(1996) 2-22.

[11] Jeevan, V K J and Gupta, B M, A scientometric analysis of research output from Indian Institute of Technology, Kharagpur, Scientometrics, 53(1) (2002) 165-168.

[12] Toutkoushian, R K, Porter, S R, Danielson, C and Hollis, $\mathrm{P} R$, Using publications count to measure an institution's research productivity, Research in Higher Education, 44(2) (2003). 121-148.

[13] Lee, C K, A scientometric study of the research performance of the Institute of Molecular and Cell Biology in Singapore, Scientometrics, 56(1) (2003) 95110.

[14] Bala, A and Gupta, B M, Growth and impact of research output of government medical college \& hospital Chandigarh: A case study, Annals of Library and Information Studies, 56 (2009) 86-94.

[15] Sharma, R M, Research publication trend among scientists of Central Potato Research Institute: A bibliometric study, Annals of Library and Information Studies, 56 (2009) 29-34.

[16] Majhi, S and Maharana, B Research productivity of physical science disciplines in sambalpur university (orrisa): A scientometrics study, Researcher World: Journal of Arts Science \& Commerce 4(1) (2012) 108115 .

[17] Baby, K and Kumaravel, J P S, Research productivity of Periyar university: A bibliometric analysis. International Research Journal of Library, Information and Archival Studies (2012)

[18] Wani, Z A, Pandit, M T and Majeed, N, Research Productivity of Indian Institute of Technology, International Journal of Library and Information Science 5(7) (2013) 216-224 